Original Research Article

\title{
Research on Social Development and Management Based on Social Network Analysis
}

\author{
Chenchen Ma* \\ Xi'an Jiaotong University, Xi'an, Shaanxi 710049, China.
}

\begin{abstract}
If you want to understand the social development and management of social network analysis, you must first know what social network analysis is. The network not only refers to the things that we usually use to surf the Internet, make calls, chat, etc., it is actually a relationship structure, a medium that links all aspects of related or unrelated things, and social network refers to the social The medium that connects various relationships is mainly to connect the individual with the social system. Everyone has his own way of behavior, has his own role in society, plays his own role, and effectively connects these individuals, just like our interpersonal communication in society, forming a social network. The Internet is actually the interaction of people in the social environment. It is similar to the Internet that we usually come into contact with. It has both restraints and development.

Keywords: Social Network; Social Development Management; Actors; Knowledge Management; Social Resource Allocation

\section{The essence of social network analysis}

Social network analysis consists of the following two main elements. The first is the actor. The so-called actor generally refers to the individual, but it is not limited to the individual. People and groups with active creativity can be an actor, like an actor. A work team, a company, an individual merchant, as long as he or they create something valuable in the same direction, can be called an actor, and the actor is like a point on a chessboard in the social network. It is the basis on which all relationships can proceed. Only with these nodes can there be subsequent connections. Speaking of connection, the second element of social networks is the relationship bond, which refers to the various connections between actors ${ }^{[1]}$. There are various relationships between people. For groups, the common relationships include cooperation, competition, confrontation, exchange, etc., and further personal relationships are more complicated, such as relatives, friends, classmates, colleagues, etc. It is the relationship bond we usually come into contact with. It also proves that each of us cannot exist alone without others.
\end{abstract}

\section{What is the composition of social networks}

We understand the main elements of social network, and then look at the form of social network, the most common of which is the group of two people, but also the most simple and basic form of social network, that is, the connection between two people, although simple, but it is the basis for the analysis of social relations, cannot be ignored. There are two groups of naturally there are three groups, it is similar to groups of two people, is composed of three people, but more than one person, has been able to make simple social relations into a small social network. Any form of human relationship can form a collection, that is, a small network, we also call sub-groups, simply speaking, small groups of society, similar to the community in schools, are a special relationship can make people connected to small groups. But we are in a group is not a single, can be a person in a lot of sub-groups, after all,

Copyright (C) 2020 Chenchen Ma

doi: 10.18282/1-e.v9i4.1675

This is an open-access article distributed under the terms of the Creative Commons Attribution Non-Commercial License (http://creativecommons.org/licenses/by-nc/4.0/), which permits unrestricted non-commercial use, distribution, and reproduction in any medium, provided the original work is properly cited.

\section{Conclusion}

As long as we reasonably carry out practical legal teaching, we can effectively exercise students' practical ability and enhance students' comprehensive ability. Therefore, when reforming legal education in our country, we should pay attention to perfecting practical legal teaching and fundamentally resolve the contradiction of students' legal knowledge.

\section{References}

[1]Yang Jiaorao. Practical legal teaching and legal education reform [J]. Legal System and Society, 2019; (17):203-204. [2]Xie Hui. Practice Skills Training Model of Law Education Based on Mobile Internet Environment [J]. Journal of Inner Mongolia Radio and TV University, 2019; (1):109-113. 
society is complex, not a single machine, we cannot live in a lifetime only in one environment, not to mention we need to develop, the actual need to contact things, into the social groups have been far beyond their own imagination. The last form is the group, that is, the collection of various sub-groups, gradually small groups, small social groups included in it, the formation of a real social network in our lives, in order to study social networks, we should be from large groups, to small groups, and finally in-depth understanding of a specific person, in order to fully analyze the social network of that person.

\section{The role or impact of social network analysis on social development and management research}

Social network analysis is the analysis of the relationship structure and attributes of social networks, mainly to analyze the social relations between individuals, groups or societies that appear to have little relationship. There is a connection between everyone in society, but we are not very interested in this, but for social network analysis, this is really a very interesting thing, they see society as a network, in which the search for two seemingly unrelated people or groups through a variety of twisting relationship ties are finally determined to have a relationship, and even through the relationship ties to guide or limit people, and ultimately affect people's thinking and actions. In this face, social network analysis is not only a technology, more like an idea and theoretical method.

Social network analysis of social development is also very broad, understand people's relationship ties, it is easy to make a difference in psychology, it is also mentioned above, the social network analysis scholars can even sit through the relationship link guidance, limit people's thinking to influence their behavior, which is similar to psychology, so in the social network analysis of social development, psychology is bound to be absent, associated with anthropology, which is similar to psychology, mainly to explore the human psychology, but the content required is not the same, anthropology is more extensive, the use of social network analysis knowledge will be more. Understand the direct social development of social network analysis, we still have a lot of not so direct but also quite in line with the trend of the times direction, such as communication science, sounds like information engineering, not much contact with society, in fact, not so, communication science not only need technology, but also need ideas, at this time, if the idea of social network analysis can be perfectly quoted, then engage in this work will be more relaxed than ordinary people, although not professional, but in the wrong professional has a great advantage.

Social network analysis in practical application is more like a tool to explain some economic, social, management and other problems, so it also determines that it is very important in enterprise knowledge management. In terms of social development, enterprise knowledge management is one of its major focus, the development of enterprises often affect the development of the country, the value of individuals will often change because of the change of enterprise value, so the introduction of social network analysis into enterprise knowledge management, that is, social development has become a matter of course. With enterprise knowledge management as the representative, social development cannot be separated from social network analysis, social development is the cumulative results of social analysts over the years.

\section{Main directions for social development}

Social development is the process of change in the rise, progress and sublimation of various elements in social relations, not only the social society of mankind, but also our natural environment. In China, this is a large collection, Each nation is a separate group, but we do not exclude each other, each nation has a mutually inclusive relationship, Therefore, social development has both vertical actions forward, and constantly optimize their own behavior, but also in the process of group development will be their own power, influence around the expansion, affecting more people to follow their own movement and development, that is, we often say horizontal development. Vertical development is mainly for the less advanced society, they also need a lot of development, and not suitable for expansion, wait until the development to saturation, at this time the whole can carry out horizontal movement, that is, the development of society is in order, not by their own mood how to change how to change how to change. At this time, the role of social network analysts has been played, they can accurately grasp the changes in society and timely out to guide the direction of social development, in the face of anachronistic social development trends can also guide people to better deal with the development of society. Social network analysts to social development is like an invisible hand, always grasp the movement of society, so there is a management of social development.

We know that good management is to maintain the normal life of human conditions, perhaps we have not noticed that there are actually many rules in human life, more obviously, laws and regulations, mandatory constraints on our code of conduct, not obviously no mandatory requirements are also many, such as shopping in the supermarket cannot be tasted in advance, it seems that no one enforces, but we all default to this rule. Then the social management is also responsible for the allocation of social resources, for the resources people have been very persistent, and we are not the average distribution of the society, resources are still so limited, how to make people satisfied, do not cause social restlessness, and the rational allocation of social resources, higher education publishing house is not a small challenge, social resources will not fall evenly on everyone's head, at this time according to the emergence of the distribution of labor to solve a major social problem, more labor distribution methods are recognized, Effective allocation of limited social resources, which is also an aspect of social management. With good social management will have good social development, social development is largely the development of social productivity, which requires most of the relationship between society and the struggle towards the same goal, from the productivity of society can be seen that a country or enterprise in social management and development research is in place, with good social management, often more effective social development of individuals in society, and not so good social management will get the opposite result.

In a summary, social network analysis is the basis of social management, and the quality of social management plays a role in social development, and finally the development of society will affect scholars to analyze the post-development society, so social network analysis of social development and management is indistingo coupled, between them to carry out organic operation, our 


\title{
Original Research Article
}

\section{The Characteristics of Japan's Preschool Education and Its Enlightenment to China's Preschool Education}

\author{
Guoliang Li ${ }^{1}$, Bixia Tan ${ }^{2}$, Wanting $\mathbf{Y i}^{3}$ \\ 1Hunan University of Arts and Science; \\ 2Hunan University of Arts and Science; \\ 3Keimyung University, South Korea
}

\begin{abstract}
In the field of world education, Japan's preschool education level has always been in the leading position, which has a great inspiration for China's preschool education. On the one hand, preschool education is closely related to economic strength, on the other hand, it is related to the development of education. Based on this, this paper analyzes the characteristics of Japan's preschool education and Its Enlightenment to China's preschool education, so as to provide theoretical reference for the future work.
\end{abstract}

Keywords: Preschool Education; Characteristics; Enlightenment

\section{Introduction}

With the rapid development of preschool education, in such an environment, preschool education will play an important role in social stability and development. In the current country, Japan's preschool education level is in the leading position. In this case, Japan's preschool education plays an important role in China's preschool education. China's education departments need to ensure the smooth development of preschool education activities according to their own actual situation.

\section{The characteristics of Japanese preschool education}

\subsection{Perfect legislation system}

Japan is a country with perfect and perfect legal system, and the laws and regulations in various fields are very clear, which makes all industries limited by these provisions and need legal basis. Japan realized the importance of preschool education at an early age, and paid more attention to the legislation of preschool education. In 1889, Japan had formulated the relevant rules of preschool education, formulated the specific education goals, and then introduced the relevant legal system to achieve the perfection of preschool legislation. Through sound legislation of preschool education, preschool education can be carried out in accordance with the law and promote the healthy and sustainable development of preschool education in Japan ${ }^{[1]}$.

\subsection{Setting up dual track preschool education institutions}

In the process of preschool education in Japan, the "two track" method is mainly used. The first track is kindergarten, which is mainly under the jurisdiction of the Ministry of education, education, culture and education. It mainly recruits children between 3 and 5 years old. It is an important institution to carry out preschool education for children. The other track is the nursery, which is mainly under the jurisdiction of the Ministry of health and welfare. It mainly recruits children between the age of 0 and 5 , and belongs to social welfare institutions. In addition, preschool education institutions can also show their own advantages in the actual development of the management system. Japanese education departments mainly use the effective combination of decentralization and centralization, not only to carry out unified management, but also to let the local have a certain degree of autonomy. This flexible way plays an important role in the sustainable development of Japan's preschool education industry ${ }^{[2]}$.

\subsection{Attach importance to the cultivation of children's independence}

Copyright (C) 2020 Guoliang Li et al.

doi: 10.18282/1-e.v9i4.1676

This is an open-access article distributed under the terms of the Creative Commons Attribution Non-Commercial License (http://creativecommons.org/licenses/by-nc/4.0/), which permits unrestricted non-commercial use, distribution, and reproduction in any medium, provided the original work is properly cited.

society will develop better and better ${ }^{[2]}$.

\section{References}

[1]Zhang Mingcang, Ouyang Kang. 2001, Higher Education Press. ISBN: 9787040088120, 429.

[2]Ma Fang. Southwest University of Political Science and Law. Chongqing, 401120. 